\title{
INVENTÁRIO DAS ÁRVORES URBANAS DA CIDADE DE REGISTRO-SP
}

\author{
Marcelo Vieira Ferraz ${ }^{12}$
}

\section{RESUMO}

A vegetação arbórea é de suma importância para as áreas urbanas por produzir uma série de benefícios aos seus habitantes. Este trabalho teve como objetivo realizar o levantamento das árvores urbanas da cidade de Registro-SP. Dezoito alunos do curso de agronomia da UNESP de Registro foram divididos em nove grupos para coleta de dados de todas as árvores existentes numa amostra de 147 quadras do município (26,4\% do total). Foram obtidos dados referentes à identificação, dimensão, biologia e entorno das espécies. Foram encontradas 558 árvores em 15,1km de vias amostradas (37 indivíduos/km), das quais 486 (87,2\%) eram espécies exóticas e 72 (12,8\%) eram nativas. As famílias mais frequentemente identificadas foram Aracaceae (63/11,4\%), Bignoniaceae (56/10,1\%), FabaceaeCaesalpinoidea (49/8,86\%) e Moraceae (49/8,86\%). A mediana da altura das espécies foi de 4 metros, variando de 0,35 a 17 metros. Em relação ao estado geral, 166 (29,7\%) árvores foram consideradas ótimas, 256 (47,9\%) boas, 118 $(21,1 \%)$ regulares e 18 (3,2\%) péssimas. A maioria das árvores estava plantada em calçadas (466/83,5\%) sendo as demais encontradas em praças, canteiro e pavimento (56/10,0\%, 35/6,27\% e 1/0,18\%, respectivamente). Das espécies estudadas, 108 (19,4\%) apresentavam afloramento da raiz nas calçadas e 13 (2,35\%) apresentavam sinais de vandalismo. O município de Registro-SP apresenta um número de árvores por $\mathrm{km}$ de vias muito abaixo do recomendado; de maneira geral, as espécies estavam em bom estado de conservação e havia predomínio de espécies exóticas.

Palavras-chave: Arborização urbana, paisagismo urbano e meio ambiente.

\section{INVENTORY OF URBAN TREES IN THE CITY OF REGISTRO-SP}

\section{ABSTRACT}

The trees are of paramount importance to urban areas to produce a series of benefits to a dwelling. This study aimed to conduct the survey of urban trees in the city of Registro-SP. Eighteen students of agronomy at UNESP in Registro were divided into nine groups to collect data from all trees in a sample of 147 blocks of the city (26.4\% of total). There were obtained data regarding identification, size, environment and biology of the species. 558 trees were found in $15.1 \mathrm{~km}$ of roads surveyed (37 individuals / km), of which 486 (87.2\%) were exotic species and 72 (12.8\%) were native. The families most frequently identified were Arecaceae (63/11, 4\%), Bignoniaceae (56/10, 1\%), FabaceaeCaesalpinoideas (49 / 8.86\%) and Moraceae (49 / 8.86\%). The median height for both species was 4 meters, ranging from 0.35 to 17 meters. Regarding the general status of 166 (29.7\%) considered optimum tree shape, 256 (47.9\%) good, 118 (21.1\%) and regular 18 (3.2\%) poor. Most trees were planted on sidewalks (466/83, 5\%) being others found in parks, bed and floor (56/10, 0\%, 35 / 6.27\% and 1 / 0, 18\%, respectively). Of those studied, 108 (19.4\%) had root outcrop on the sidewalk and 13 (2.35\%) showed signs of vandalism. The municipality of Registro-SP features a number of trees per km of track well below the recommended, in general, the species were in good condition and there was a predominance of exotic species.

Keywords: Urban tree, landscape and urban environment.

\footnotetext{
${ }^{1}$ Professor Assistente Doutor de Tecnologia, Floricultura e Paisagismo da UNESP- Registro- SP. Rua Nelson Brihi Badur, 430 Vila Tupy- Registro -SP. CEP:11.900-000. E- mail: ferraz@registro.unesp.br

2 (recebido em 14.04.2011 e aceito para publicação em 15.06.2012)

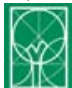




\section{INTRODUÇÃO}

A vegetação arbórea é de suma importância para as áreas urbanas por produzir benefícios como diminuição da poluição sonora e atmosférica, conforto térmico e lumínico, controle do ciclo hidrológico, entre outros. Souza (2009) cita que a arborização urbana é um fator determinante para nosso bem estar. Para que possamos desfrutar destes benefícios, cuidar do patrimônio arbóreo das cidades se torna uma tarefa fundamental. Dentro deste contexto CPFL (2011) cita que, o plantio e a poda merecem grande atenção. Paiva (1996) cita que a coexistência harmoniosa da arborização urbana com estruturas de distribuição de energia elétrica contribui com a arborização existente, reduzindo os custos das prefeituras com manutenção. Para Romani (2011) a temática da arborização urbana no Brasil é tema novo que evolui lentamente, sendo que a participação das administrações públicas e da comunidade deve cumprir papéis bem definidos. Para Crestana et al. (2007) os responsáveis pela elaboração de políticas públicas para arborização urbana devem elaborar normativas e conhecer, quantitativamente, as características do espaço a ser implantado o programa de arborização pública, somente depois é que se pode desenhar e estabelecer uma cobertura arbórea mais eficiente para as cidades brasileiras. Já para Paiva (2009), o bom planejamento é aquele em que se conhece as características quali-quantitativas das árvores urbanas, que possibilite a realização de intervenções com grande chance de sucesso. Miranda e Carvalho (2009) citam que a pobreza em espécies nas ruas acarreta maior suscetibilidade a pragas e doenças e para buscar maior heterogeneidade é muito importante a elaboração do Plano de Arborização Urbana, pois através desse é que se pode elaborar um diagnóstico preciso das vias arborizadas. Assim será possível criar e refletir sobre novas formas de pensar a cidade para criar projetos que atendam os desejos da população e das questões ambientais. Faltam técnicos e informações especializadas em Arborização Urbana, o que causam grandes transtornos (MIRANDA; CARVALHO, 2009). A escolha de uma espécie deve ser baseada, primeiramente, em inventário elaborado pelo município para saber exatamente o que a cidade tem plantado, em que local e onde o projeto pode atender as necessidades de cada cidade. Michi e Couto (1996) citam que o monitoramento das condições das árvores é importante para priorizar os recursos humanos e financeiros destinados a arborização, demonstrar também a diversidade das espécies e das idades, corrigir possíveis problemas que poderiam causar danos ao público ou propriedades, definir espécies mais adaptadas e viveiros fornecedores de mudas de melhor qualidade e, ainda, identificar espécies mais suscetíveis ao ataque de pragas e doenças.

Conhecer o porte das árvores, distribuição e localização se torna tarefa fundamental no planejamento urbano, uma vez que as cidades estão sofrendo com um alto grau de urbanização e com todos os malefícios que isto pode acarretar ao ambiente urbano como superfícies acumuladoras e refletoras de calor, alta concentração de poluição e população e intensas áreas impermeabilizadas. Aguirre Junior e Lima (2007) relatam que a utilização de árvores de médio e grande é imprescindível para a mitigação dos efeitos causados pela ação humana sobre o meio. Os mesmos autores citam que estas árvores podem reduzir a amplitude térmica e melhorar as condições microclimáticas na cidade, já os arbustos e árvores de pequeno porte, não garantem os mesmo efeitos propiciados pelas árvores de médio e grande porte. Para Toscan et. al. (2010) outro fator importante para um planejamento é a prioridade que se deve ter com as plantas nativas, pois as espécies exóticas podem causar diversos danos ao meio ambiente, como a perda da diversidade, modificações nos ciclos e características naturais dos ecossistemas atingidos, alterações paisagísticas e algumas vezes conseqüências econômicas.

Este trabalho teve como objetivo realizar o levantamento das árvores urbanas da cidade de Registro-SP, com identificação das espécies nativas e exóticas presentes e suas condições sanitárias. INVENTÁRIO DAS ÁRVORES... 
Buscou-se conhecer as famílias de plantas e seu estado geral, bem como a distribuição das árvores, sua localização, presença de injúrias e fornecer dados ao poder público para elaboração de um Plano de Arborização Urbana.

\section{MATERIAS E MÉTODOS}

\section{Área de estudo}

A cidade de Registro está situada no Vale do Ribeira no Estado de São Paulo. O Município conta com área de $742 \mathrm{Km}^{2}$, dos quais 78,54 Km² são urbanos. Possui uma população de 54.279 habitantes, sendo 48.187 na cidade e 6.092 na zona rural (IBGE, 2011). A cidade tem clima quente e úmido, com temperatura máxima de $35^{\circ} \mathrm{C}$, mínima de $13^{\circ} \mathrm{C}$ e a média anual de $24^{\circ} \mathrm{C}$. Por sua localização, a cidade está inserida na grande região do bioma Mata Atlântica da Floresta
Ombrófila Densa. A umidade relativa do ar é de $84 \%$ (média anual), com Índice pluviométrico de 1500 mm (média anual) e apresenta 1600 horas de sol (média anual). O município está a uma altitude de $15 \mathrm{~m}$ acima do nível do mar, sendo dividido pelo Rio Ribeira do Iguape com economia baseada na Agricultura, pecuária, indústria de beneficiamento e comércio (FERRAZ; NOGUEIRA, 2009).

\section{Coleta de dados}

No ano de 2009 entre os meses de março e abril, foi realizado o levantamento da arborização pelo método de inventário quali-quantitativo, por amostragem, considerando os quarteirões previamente sorteados, suas respectivas ruas e todos os indivíduos de porte arbóreo e arbustivo da área urbana. Os dados coletados foram anotados em formulário específico para cada espécime, baseado na metodologia proposta por Silva Filho (2002). Para a realização do inventário a cidade foi dividida em quatro partes, posteriormente foram sorteados 147 quarteirões (26,4\% do total). Dezoito alunos do curso de agronomia da UNESP de Registro foram divididos em nove grupos. Os quarteirões sorteados foram percorridos a pé para posterior identificação das espécies e características do entorno. O total de vias em quilômetros da cidade de Registro é de 135, sendo que para o trabalho foram amostrados e percorridos a pé $15,1 \mathrm{Km}$ destas vias. A cidade de Registro possui apenas seis praças. Neste trabalho duas praças estavam localizadas nas quadras sorteadas. Baseado no método proposto por Silva Filho (2002) foram diagnosticados os seguintes itens: identificação do indivíduo (número, endereço, nome popular e nome científico), altura geral (m), posição do plantio (junto a guia, junto ao muro, centro do canteiro), largura da calçada(m), largura do leito de rolagem (m), distribuição das árvores de acordo com o estado geral, localização e presença de injúrias e fitossanidade das árvores lesionadas. Após essa etapa de campo, os dados foram avaliados com auxílio de softwares visando validar a amostragem feita e obter resultados a partir dos dados coletados que caracterizam a situação da arborização urbana. Os dados foram analisados, seguindo a metodologia de Crestana et al. (2007) para estruturar um inventário por amostragem.

\section{RESULTADOS E DISCUSSÃO}

Das 558 árvores analisadas, 486 (87,20\%) eram espécies exóticas e apenas 72 (12,80\%) nativas. Registro apresentou um baixo índice de espécies nativas o que refletiu a falta de planejamento da arborização urbana da cidade no passado. 
Paiva (2009) cita que não se deve excluir espécies exóticas de projetos de arborização urbana e paisagismo, mas é importante que o autor do projeto observe que as árvores plantadas cumpram funções ambientais e interações com a fauna nativa, sendo que o uso de espécies exóticas põe em risco essas interações. Toscan et. al. (2010), citam que a maioria das plantas arbóreas usadas na arborização urbana das cidades é de espécies exóticas, apesar de a flora nativa contar com espécies de grande beleza paisagística. Para Miranda e Carvalho (2009) é de grande importância que se dê prioridade as plantas nativas, pois as espécies exóticas podem causar diversos danos ao ambiente, como perda de biodiversidade, modificações nos ciclos e características naturais dos ecossistemas.

Também foi observado que 108 (19,40\%) das espécies estudadas apresentavam afloramento de raiz nas calçadas, o que em muitos casos acarreta o impedimento da passagem por pedestres $\mathrm{e}$ cadeirantes. Este dado reflete a pouca preocupação em se fazer a descompactação do solo, a confecção de covas e a escolha de espécies ideais na cidade. Miranda e Carvalho (2009) citam que as raízes podem causar problemas com calçadas, quebrandoas, dificultando a passagem de pedestres. De acordo com Martelli e Barbosa Junior (2010) é importante fazer planejamento antes do plantio de árvores nas cidades brasileiras, pois a não realização deste procedimento pode causar sérios prejuízos, como rompimento de fios de alta tensão, interrupções no fornecimento de energia elétrica, entupimento em redes de esgoto, obstáculos para circulação e acidentes diversos. Paiva (2009) observou que valores abaixo de $0,5 \mathrm{~m}^{2}$ de espaço livre nas calçadas, comprometem o desenvolvimento das árvores uma vez que esse espaço é muito pequeno para o bom estabelecimento da planta, de forma que essa situação se agrava para aquelas espécies de maior DAP. Segundo Jim (2011) a compactação do solo é outro problema sério que deve ser levado em consideração, pois ela pode provocar a queda de árvores no futuro. Segundo o mesmo autor estes efeitos negativos estão relacionados as propriedades físicas e físico-químicas do solo e que a instalação de tubos de aeração e drenagem poderia aliviar os maus efeitos da compactação.

Outro item analisado foram as famílias das plantas. Observou-se que as famílias mais frequentemente identificadas foram Aracaceae (63/11,40\%), Bignoniaceae (56/10,10\%), FabaceaeCaesalpinoideae (49/8,86\%), Moraceae (49/8,86\%), Fabaceae-Faboideae (28/5,10\%), Myrtaceae (28/5,10\%), Rutacea (21/3,80\%), FabaceaeMimosoideae (21/3,80\%) e Outras e com certa de (243/42,98\%) (Figura 1).

Figura 1: Distribuição das árvores urbanas da cidade de Registro-SP, de acordo com as famílias.

Figure 1: Distribution of urban trees in the city of Registro-SP according to the families.

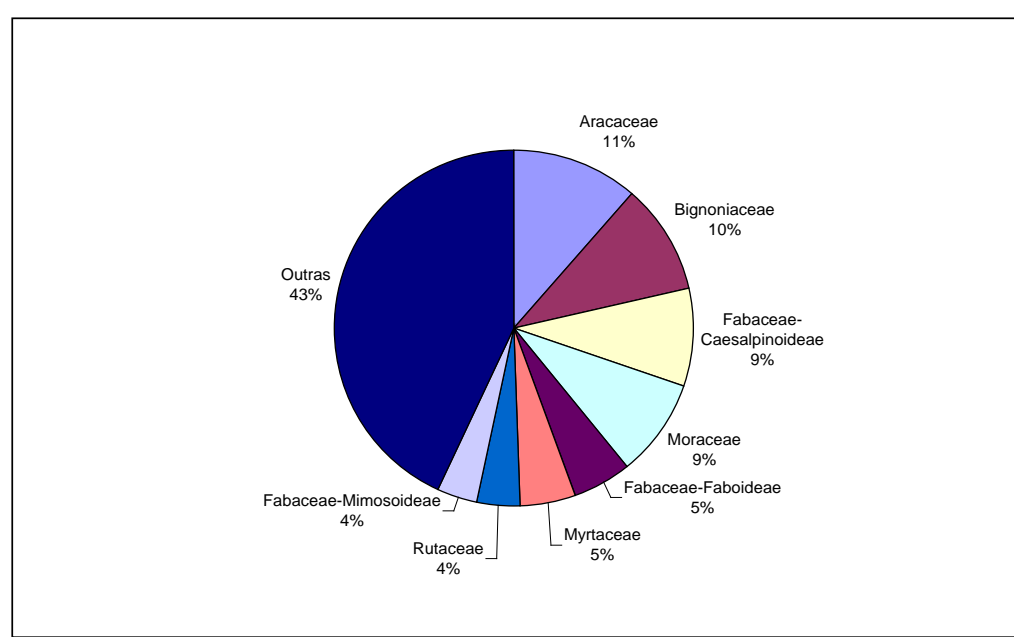

Com os dados coletados observouse que a distribuição das famílias é altamente irregular, fato também observado por Rossatto et al. (2008) ao pesquisar as famílias das espécies da cidade de Assis- SP. Observou-se em Registro um número elevado da família Moraceae (49/8,86\%), sendo que a espécie que melhor representou esta família foi o Ficus (Ficus benjamina).

INVENTÁRIO DAS ÁRVORES... 
Outra família que também contribuiu para este problema foi a Aracaceae (63/11,4\%), cujo exemplar mais observado foi a areca bambú (Dypsis lutescens). O caule cespitoso e espesso da areca contribuiu para o afloramento da raízes, o que levou, em alguns casos, a quebra das calçadas. Segundo Rossatto et al., (2008) os problemas são constantemente causados pela abundância de espécies e que a estratégia para melhorar a arborização é a implantação de um plano diretor municipal para a arborização urbana, de modo que se estabeleça regras e controle de maneira efetiva. Segundo Paiva (2009) é recomendável a utilização de espécies de acordo com seu porte e o espaço físico existente no local a ser realizado o plantio.

Outro resultado observado foi a distribuição das árvores urbanas de acordo com seu estado geral de conservação (Figura 2). Em relação ao estado geral, 166 (30,00\%) eram árvores consideradas ótimas, 256 (46,00\%) boas, 118 (21,00\%) regulares e 18 (3,00\%) péssimas. Grande parte das árvores em estado regular (21,00\%) ou péssima (3,00\%) era em função de atos de vandalismo ou uso de técnicas erradas de podas. A maioria dos problemas observados foi em função dos moradores que plantaram espécies erradas em locais impróprios, sem os padrões recomendados.

Figura 2: Distribuição das árvores urbanas do cidade de Registro-SP, de acordo com o estado geral.

Figure 2: Distribution of urban trees in the city of Registro-SP according to the condition.

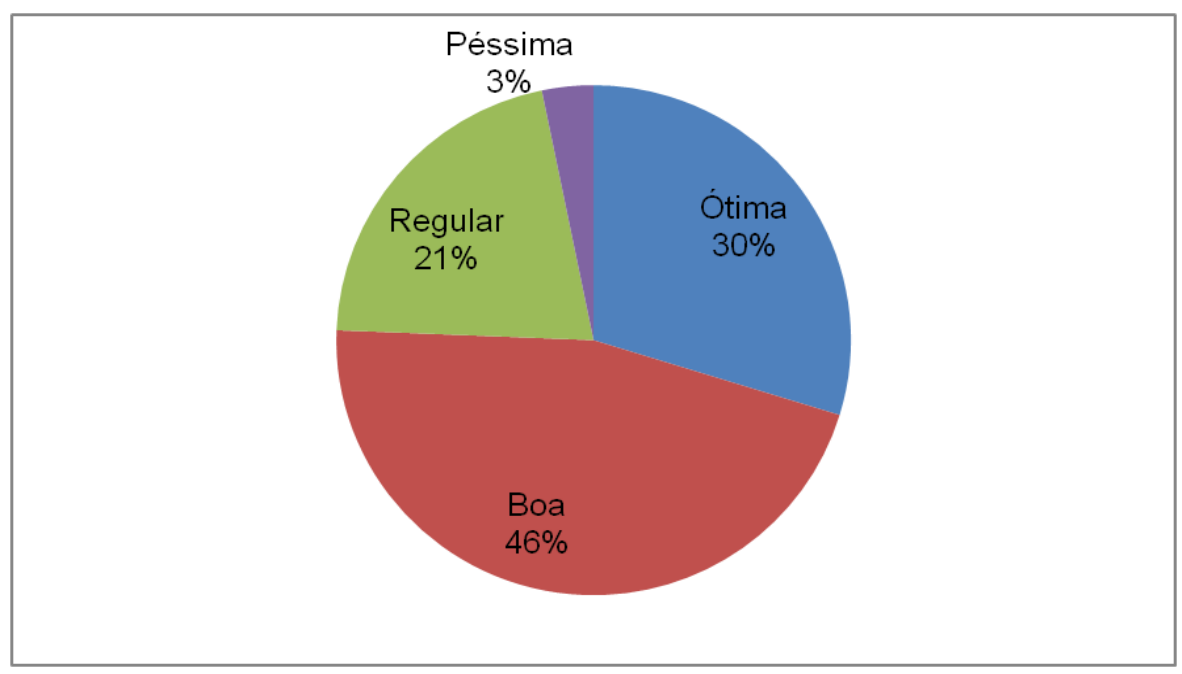

A respeito da posição das árvores, das 558 árvores registradas, 245 estavam plantadas junto a guia, 90 (16,12\%) plantadas junto ao muro, 216 (38,70\%) no centro dos canteiros e 7 $(1,25 \%)$ em outros lugares.

Não houve uma preocupação do Poder Público e das pessoas em se plantar árvores no local correto, uma vez que apenas 216 (38,70\%) estavam plantadas em local correto. Para Lacerda et al. (2010), é preciso que os órgãos públicos promovam campanhas educativas para instruir a população sobre os benefícios de uma arborização adequada e, assim, criar uma sociedade consciente que irá participar ativamente na manutenção do arboreto público.

Segundo dados observados na Figura 3, das 558 árvores analisadas a maioria, cerca de 466 $(83,51)$ estavam plantadas em calçadas, 56 (10,04\%) em praças, 35 (6,27\%) em canteiros e $1(0,18 \%)$ no
Poucos são os cidadãos que tem consciência que o Poder Público tem responsabilidade nestes fatos. Lacerda et. al. (2010) ao analisar os dados de Piranhas-PB notou que ao serem argüidos sobre quem seria responsável pela arborização da cidade, 46,40\% dos entrevistados disseram que era o próprio morador, 39,20\% atribuíram a prefeitura e apenas $14,40 \%$ citaram o profissional contratado pelo morador.

pavimento. Isto reflete que a cidade, além de possuir pequeno número de árvores, cerca de 44,43 unidades $/ \mathrm{km}$, elas estão localizadas ao longo do passeio público e em pequena quantidade nas duas Marcelo Vieira Ferraz 
praças pesquisadas. Segundo Paiva (2009) os exemplares arbóreos encontrados nas calçadas públicas de Cosmópolis-SP sofreram as maiores pressões antrópicas, estando sujeitas às injúrias físicas pela ação do homem. Martins et al. (2010) concluíram que é necessário escolher a árvore certa para o espaço certo, com a finalidade de evitar eventuais transtornos pela incompatibilidade da árvore com a área escolhida para o plantio, essa prática contribui para melhor saúde do vegetal.

Figura 3: Distribuição das árvores urbanas de cidade de Registro-SP, de acordo com a localização.

Figure 3: Distribution of urban trees in the city of Registro-SP according to location.

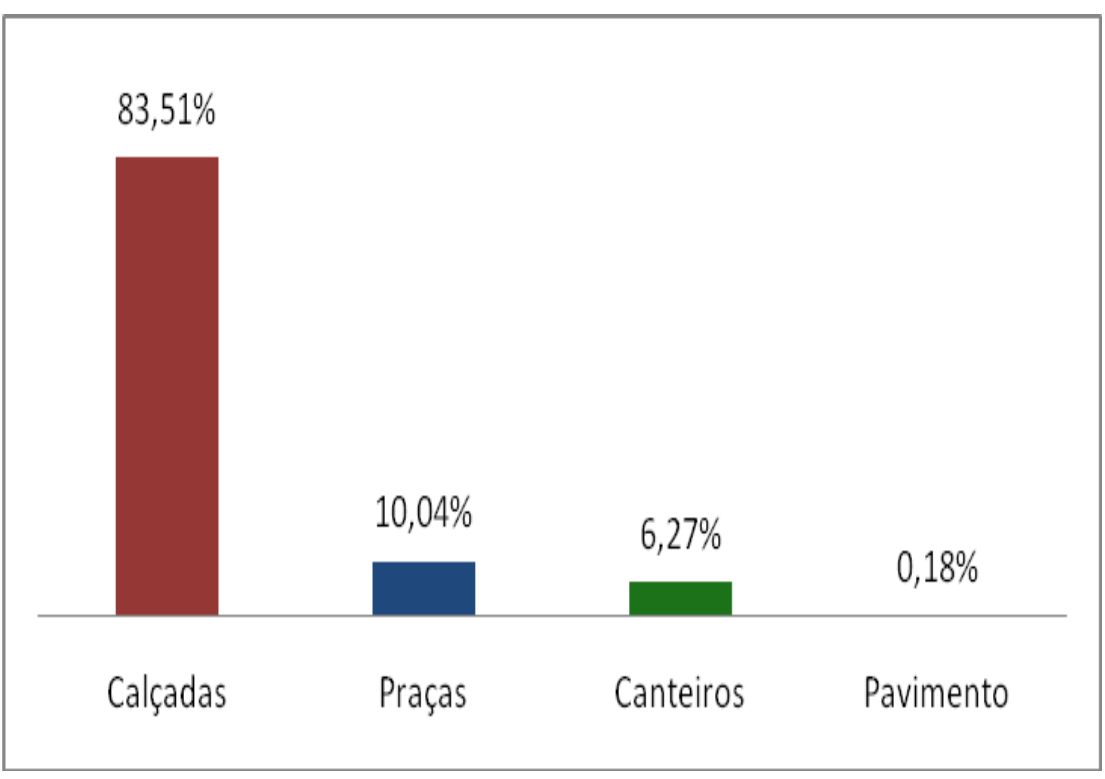

Das 558 árvores da cidade de Registro-SP estudadas, de vandalismo e apenas 42 (7,50\%) árvores não 245 (44,0\%) tiveram presença de lesões, 258 foram avaliadas (Figura 4).

(46,20\%) ausência, 13 (2,30\%) apresentaram sinais

Figura 4: Distribuição das árvores urbanas da cidade de Registro-SP, de acordo com a presença de injúrias.

Figure 4: Distribution of urban trees in the city of Registro-SP according to the presence of injuries.

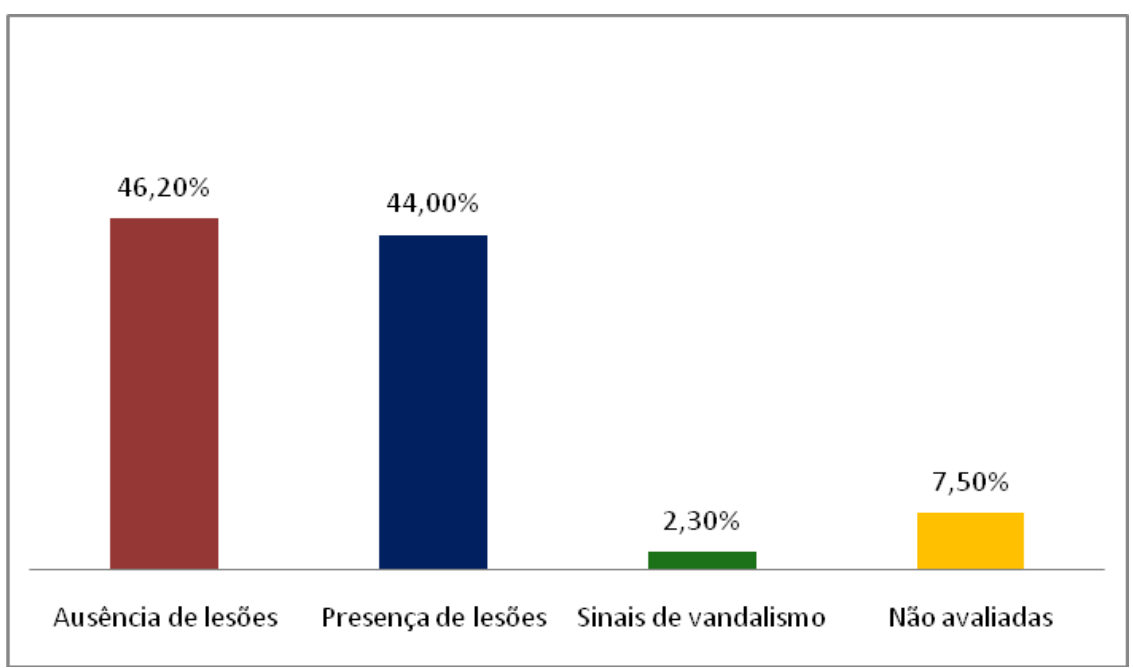


Nas árvores lesadas, observou-se que $40 \%$ estavam com fungos, 30\% com insetos, 15\% com bactérias e
15\% com outras lesões. Estas lesões deixaram as árvores com aparência não satisfatória (Figura 5).

Figura 5: Distribuição das árvores urbanas da cidade de Registro-SP, de acordo com a fitossanidade das árvores lesadas.

Figure 5: Distribution of urban trees in the city of Registro-SP according to the plant trees damaged.

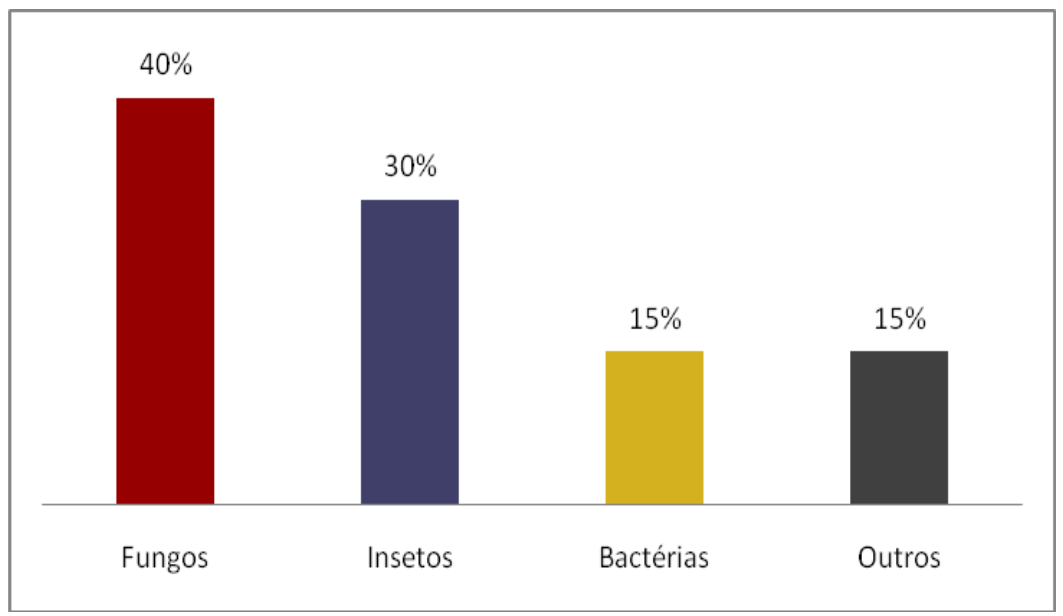

Neste trabalho observou-se que a altura média das árvores na cidade de Registro foi de 13,50 metros, sendo a largura média das calçadas de 2,32 metros e o leito de rolagem de 8 metros. Este resultado pode justificar a pequena quantidade de árvores plantadas na cidade, uma vez que estas medidas dificultam projetos de arborização urbana.

Outro aspecto analisado foi a pavimentação em que estas árvores foram plantadas. Constatou-se que das 558 árvores analisadas, 329 (58,96\%) foram plantadas sob o pavimento de concreto, 206 (36,91\%) sob a terra, $22(3,94 \%)$ sob a grama, e apenas 1 $(0,17 \%)$ em outro pavimento. Verifica-se que a maioria das calçadas da área de estudo são constituída de concreto e que a utilização de calçadas verdes ou ecológicas em que se utiliza o pavimento grama ainda é baixa na cidade. Pires et al. (2010) citam que os conflitos existentes entre as árvores e as calçadas na ocupação do espaço são um dos principais problemas na arborização viária de uma cidade.

\section{CONCLUSÕES}

Com essa pesquisa verificou-se que a arborização urbana na cidade de Registro-SP não foi planejada, uma vez que a cidade possui um número baixo de espécies nativas e um número muito alto de exóticas. Existe um grande número de espécies exóticas plantadas em local inadequado, o que contribui para aumentar os índices de afloramento de raízes das árvores na cidade.

$\mathrm{Na}$ cidade ocorre uma distribuição irregular das famílias, onde se observou predomínio da Moraceae e da Aracaceae, sendo não indicadas para a arborização das vias públicas. Adicionalmente, observou-se grande número de árvores com lesões, refletindo um estado de má conservação do arboreto público. A arborização urbana da área estudada mostrou-se baixa e mal distribuída sendo que a maioria das árvores está plantada nas calçadas de concreto e junto a guia; praticamente não há arborização urbana nos canteiros centrais das avenidas da cidade. Verificou-se através desta pesquisa que Registro apresenta ruas e calçadas estreitas, o que dificulta a arborização da cidade.

Por meio de ações diretas e campanhas educativas para a população, o Poder Público da cidade de Registro-SP necessita substituir, gradativamente, espécies exóticas por nativas, diversificar e adequar as famílias a serem plantadas, aumentar o plantio em canteiros centrais de avenidas e praças, intensificar a criação de calçadas verdes bem como estimular a manutenção das árvores da cidade. 


\section{AGRADECIMENTOS}

A Prefeitura Municipal de Registro-SP pela disponibilização de informações e pelo apoio no I Workshop Sobre Arborização Urbana do Vale do
Ribeira. Aos alunos da UNESP de Registro por ajudarem na coleta de dados para este inventário.

\section{REFERÊNCIAS BIBLIOGRÁFICAS}

Companhia Paulista de Força e Luz- CPFL. Arborização Urbana Viária. Disponível:

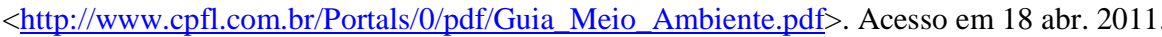

CRESTANA, M. S. M. (org.) et al. Árvores \& Cia. Campinas: CATI, 2007. 132p.

FERRAZ, M. V., NOGUEIRA, D. M. Workshop Sobre Arborização Urbana do Vale do Ribeira. Arborização Urbana Para o Município de Registro-SP. Botucatu: FEPAF, 2009. 68 p.

IBGE. Instituto Brasileiro de Geografia Estatística- Disponível em: <http://www.ibge.gov.br/home/estatistica/populacao/censo2010/default.shtm>. Acesso em 05 abr. 2011.

JIM, C. Y. Soil Compaction as a Constraint to Tree Growth in Tropical \& Subtropical Urban Habitats. Disponível em: $<$ http://journals.cambridge.org/action/displayAbstract;jsessionid=04A98873D9BD78C0ED1377683511FD10.journal s?fromPage=online\&aid=5959188. $>$ Acesso em 23 dez. 2011.

AGUIRRE JUNIOR, J. H.; LIMA, A. M. L. P. Uso de árvores e arbustos em cidades brasileiras. Revista da Sociedade Brasileira de Arborização Urbana, v.2, n.4, p.50-66, 2007.

LACERDA, N. P.; SOUTO, P. C.; DIAS, R. S.; SOUTO, L. S.; SOUTO, J. S. Percepção dos residentes sobre a arborização da cidade de São José de Piranhas-PB. Revista da Sociedade Brasileira de Arborização Urbana, v.5, n.4, p.81-95, 2010.

MARTELLI, A.; BARBOSA JUNIOR, J. Análise da Incidência de Supressão Arbórea e suas principais causas no perímetro urbano do Município de Itapira-SP. Revista da Sociedade Brasileira de Arborização Urbana, v.5, n.4, p.96-109, 2010.

MARTINS, L. F. V.; ANDRADE, H. H. B.; DE ANGELIS, B. L. D. Relação entre podas e aspectos fitossanitários em árvores urbanas na cidade de Luziana, Paraná. Revista da Sociedade Brasileira de Arborização Urbana, v.5, n.4, p.141-155, 2010.

MICHI, S. M. P.; COUTO, H. T. Z. Estudo de dois métodos de amostragem de árvores de uma rua na cidade de Piracicaba-SP. I Curso em treinamento sobre poda em espécies arbóreas florestais e de arborização urbana. s/n .Piracicaba-SP, 1996. 
MIRANDA, T. O. CARVALHO, S. M. Levantamento Quantitativo e qualitativo de indivíduos arbóreos presentes nas vias do Bairro da Ronda em Ponta Grossa-PR. Revista da Sociedade Brasileira de Arborização Urbana, v.4, n.3, p.143-157, 2009.

PAIVA, A. V. Programa de arborização urbana: normas e procedimentos adotados pela Companhia paulista de Força e Luz- CPFL I Curso em treinamento sobre poda em espécies arbóreas florestais e de arborização urbana. s/n .Piracicaba-SP, 1996.

PAIVA, A. V. Aspectos da arborização urbana do centro de Cosmópolis-SP. Revista da Sociedade Brasileira de Arborização Urbana, v.4, n.4, p.17-31, 2009.

PIRES, N. A. M. T.; MELO, M. S.; OLIVEIRA, D. E.; SANTOS, S. X. A arborização urbana do Município de Goiandra-GO - Caracterização Quali-Aquantitativa e proposta de manejo. Revista da Sociedade Brasileira de Arborização Urbana, v.5, n.3, p.185-205, 2010.

ROMANI, G. N. Análise Florística Fitossociológica e Qualitativa da Arborização na Praça XV de Novembro em Ribeirão Preto, SP. Dissertação (Mestrado) - Jaboticabal, 2011. 58p. Faculdade de Ciências Agrárias e Veterinárias, Universidade Estadual Paulista

ROSSATTO, D. R.; TSUBOY, M. S. F.; FREI, F. Arborização urbana na cidade de Assis-SP; uma abordagem quantitativa. Revista da Sociedade Brasileira de Arborização Urbana, v.3, n.3, p.1-16, 2008.

SILVA FILHO, D. F. Cadastramento informatizado, sistematização e análise da arborização das vias públicas da área urbana do Município de Jaboticabal, SP. Jaboticabal, 2002. 81p. Dissertação (Mestrado), Faculdade de Ciências Agrárias e Veterinárias, Universidade Estadual Paulista.

SOUZA, M. A. L. B. Maximização das funções ecológicas, ambientais e estéticas das árvores no planejamento da arborização urbana. I Workshop de arborização urbana no Vale do Ribeira-SP. Registro-SP, 2009.

TOSCAN, M. A. G.; RICKLI, H. C; BARTINICK, D.; SANTOS, S.; ROSSA, D. Inventário e análise da arborização do Bairro Vila Yolanda, do Município de Foz do Iguaçu-PR.. Revista da Sociedade Brasileira de Arborização Urbana, v.5, n.3, p.165-184, 2010. 